\title{
O Retrocesso Normativo Ambiental no Brasil Análise dos Reflexos Jurídicos da Globalização Econômica e do Neoliberalismo
}

\author{
Abili Lázaro Castro de Lima \\ Professor-adjunto do Curso de Direito e do PPGD da Uni- \\ versidade Federal do Paraná das disciplinas Sociologia \\ do Direito, Direito e Sociedade e Prática de Docência em \\ Direito. Membro da Sociedade Brasileira de Sociologia. \\ abili-lima@uol.com.br
}

\section{Júlio César Garcia}

Doutorando em Direito do Programa de Pós-Graduação em Direito da Universidade Federal do Paraná, membro do Núcleo de estudos do Direito Administrativo, Urbanístico, Ambiental e Desenvolvimento - Pró-Polis, docente do curso de Direito da Unioeste, campus de Foz do Iguaçu-PR, e integrante do Grupo de Estudos em Direito Ambiental, Internacional e Sustentabilidade. jcgconsultoria@gmail.com

\section{Resumo}

Após décadas de avanço e sistematização, o Direito Ambiental começa a sofrer movimentos de alteração normativa em todo o mundo, os quais podem configurar retrocessos nos padrões de proteção ambiental. Uma das principais causas identificadas é a combinação da globalização econômica com o neoliberalismo, que produzem reflexos sobre o Direito, um fenômeno de internacionalização dos centros de produção e controle das normas jurídicas. Este sistema influencia e determina as tomadas de decisão no âmbito interno brasileiro, superando a tradicional concepção do poder centrado no Estado. 0 objetivo deste artigo é analisar o papel que a globalização econômica e o neoliberalismo desempenham no Direito, especialmente quanto as suas consequências para a configuração de retrocessos normativos ambientais no Direito pátrio, tomando como exemplo o recente caso da aprovação do novo Código Florestal Brasileiro. Com base no método dedutivo e por meio da revisão bibliográfica, a partir de uma delimitação conceitual do retrocesso ambiental, é realizada uma análise crítica das principais características associadas à globalização do direito e o neoliberalismo, e 0 seu real potencial de diminuir ou prejudicar o status da proteção jurídica do meio ambiente no Brasil.

Palavras-Chave: Globalização. Retrocesso Normativo Ambiental. Novo Código Florestal Brasileiro. 


\title{
The Environmental Law Retrogression on Brazil: Analysis of the Juridical Effects from Economical Globalization and Neoliberalism
}

\begin{abstract}
After decades of improvement and systematization the Environmental Law starts to undergo changes that can configure normative setbacks on environmental protection standards. One of the main reasons is the combination of economic globalization and neoliberalism, which produce consequences to law, a phenomenon of internationalization of the production and control centers for law. This system influences and commands the decision making process on brazilian national law, overtaking the traditional concept of state centered power. The objective of this article is to analyse the role that economic globalization and neoliberalism present on law, specially its consequences on environmental law retrogressions on Brazil, taking as example the recent approval of the New Brazilian Forest Code. Based on the deductive method and through the literature review, after a conceptual delimitation of environmental retrogression, it analyses critically the main characteristics associated to law globalization and neoliberlism, and its real potential to decrease or harm the juridical status of brazilian environmental protection.
\end{abstract}

Keywords: Globalization. Environmental Law Retrogression. Brazilian New Forest Code.

\section{Sumário}

1. Introdução. 2 A Globalização econômica, neoliberalismo e direito. 30 Retrocesso Ambiental. 4 A Globalização do Direito, o Neoliberalismo e o Retrocesso no Direito Ambiental Brasileiro. 5 Conclusões. 6 Referências. 


\section{INTRODUÇÃO}

O mundo atual é marcado pela globalização econômica e pelo neoliberalismo, verdadeiras forças atuantes não apenas na economia, mas também nas tradições culturais, nas relações interpessoais e na realização da política.

Estas forças também geram consequências sobre o Direito, especialmente moldando e transformando os centros de tomadas de decisão e a própria produção normativa. Para além do Direito monopolizado pelo Estado, o mundo atual observa fontes plurais do Direito, com destaque para a atuação das empresas transnacionais e a imposição de valores ligados ao neoliberalismo.

Este fenômeno, por sua própria natureza, ocorre em todo o mundo e, portanto, produz efeitos também no Brasil. Após décadas de avanços, o Direito Ambiental brasileiro passou a sofrer abalos e retrocessos normativos nos últimos anos, demonstrando uma verdadeira tendência de diminuição, descaracterização ou eliminação dos padrões de proteção ambiental já alcançados.

A pesquisa utilizou o método dedutivo e a realização de revisão bibliográfica especializada. O objetivo deste artigo é discutir e apontar os papéis da globalização econômica e do neoliberalismo na produção de retrocessos ambientais no direito brasileiro, destacando o recente caso da aprovação do novo Código Florestal.

\section{A GLOBALIZAÇÃO ECONÔMICA, NEOLIBERALISMO E DIREITO}

Apresentar a globalização é um daqueles desafios de explicar uma experiência comum a todos, mas cujas percepções podem variar amplamente. Por se tratar de um fenômeno marcado por mutações nos últimos 
tempos e com reflexos sobre diversas áreas do conhecimento, ainda não há bases teóricas e empíricas que forneçam um panorama geral amplamente aceito como referência sobre o tema.

Dentre as várias definições existentes, Anthony Giddens, na obra As consequências da modernidade, publicada pela Unesp em 1991, define a globalização “[...] como a intensificação das relações sociais em escala mundial, que ligam localidades distantes de tal maneira que os acontecimentos locais são modelados por eventos ocorrendo a muitas milhas de distância e vice-versa” (Giddens, apud Lima, 2002, p. 124-125).

Neste mesmo sentido, apoiado também na noção de interconexões de David Held, Abili Lázaro Castro de Lima propõe a construção de um tipo ideal da globalização: "ela implica uma crescente interconexão em vários níveis da vida cotidiana a diversos lugares longínquos no mundo” (Lima, 2002, p. 127).

Observa-se assim que, dentre as características marcantes reconhecidas no conceito da globalização, está a interconexão, seja entre pessoas, locais, economias ou culturas. Estas conexões podem levar, na maioria dos casos, a interdependências, com a troca de ideias, bens, informações, leis e capitais. Além disso, podem surgir dependências ou interprisões, condicionando e submetendo grupos explorados por elites mundiais.

Entre as diversas dimensões nas quais o fenômeno da globalização produz seus efeitos, verifica-se que "a globalização do mercado está fundada num conjunto de medidas e de políticas presentes na teoria econômica denominada neoliberalismo" (Lima, 2002, p. 156).

De acordo com Perry Anderson, o neoliberalismo nasceu após o término da Segunda Guerra Mundial nos países europeus e nos Estados Unidos, onde prevalecia o capitalismo. Para o referido autor, "trata-se de um movimento de reação, em âmbito teórico e político, ao Estado social, 
o qual implementava medidas intervencionistas na sociedade e no mercado, garantindo e tutelando os direitos sociais e o bem-estar da população (Anderson, apud Lima, 2002, p. 157-158).

Em uma abordagem crítica da História, Chomsky afirma que o termo neoliberalismo sugere um sistema de princípios que, ao mesmo tempo em que é novo, baseia-se nas ideias liberais clássicas de Adam Smith. Também conhecido como Consenso de Washington, segue uma expressão que sugere algo a respeito da ordem global. Assim, "essas doutrinas não são novas, e seus pressupostos básicos estão muito distantes daqueles que animaram a tradição liberal desde o Iluminismo” (Chosmky, 2002, p. 9).

Apesar da aparência que os defensores e propagadores buscam dar ao neoliberalismo, associando-o à liberdade de iniciativa e de ampla oportunidade de desenvolvimento individual, na prática seus efeitos têm se mostrado altamente nocivos para a grande maioria dos seres humanos e para a própria estrutura do Estado Democrático de Direito.

Segundo Robert W. McChesney, o neoliberalismo é o paradigma econômico e político que define o nosso tempo, podendo ser definido como: “[...] um conjunto de condições de políticas e processos que permitem a um número relativamente pequeno de interesses particulares controlar a maior parte possível da vida social com o objetivo de maximizar seus benefícios individuais” (McChesney, apud Chomsky, 2002, p. 3).

Nos tempos modernos tal ideologia ganhou adeptos, impulsionada pela ampla divulgação por parte dos Estados Unidos da América, e passou a dominar o cenário internacional, alterando profundamente a relação política dos cidadãos com o Estado.

Neste sentido, esta é a observação crítica de Abili Lázaro Castro de Lima (2002, p. 174): 
A globalização econômica, alicerçada sobre a ideologia neoliberal, faz com que o Estado deixe de ser um espaço privilegiado para participação política e para a conquista e defesa dos direitos dos cidadãos, passando a constituir uma seara que serve de "guardiã" do livre mercado.

A partir da noção de submissão dos cidadãos às decisões das transnacionais, que ocuparam o espaço público da política a partir da globalização, Abili Lázaro Castro de Lima (2002) também aponta para o retraimento da esfera pública e a diminuição da participação popular no palco político, juntamente com a apatia política e o esvaziamento do poder do Estado.

Tal situação está associada ao declínio da participação política dos cidadãos com o declínio do Estado e a transferência das decisões políticas para as mãos das empresas transnacionais e organizações internacionais (Lima, 2002). Devido ao seu caráter fluido, o poder muda de mãos, de centros de interesse, de protagonistas, mas nunca deixa de existir, de ser exercido. Se o poder decisório sai do Estado e de seus mecanismos representativos do povo, ele é assumido por outra instância.

Naturalmente, o Direito assume papel importante neste jogo de poderes, ora atuando como causa da globalização, ora refletindo suas consequências. Seja no viés ideológico que se assume na interpretação judiciária das normas, seja pela perda de poder regulador do Estado, o Direito do mundo globalizado padece de um parlamento criador de normas marcadas pela ausência de democracia e participação política.

Se os próprios interessados não têm mais voz na elaboração normativa, interesses transnacionais atropelam as instituições, as leis e os ordenamentos jurídicos dos Estados. Sob a justificativa da defesa de princípios tidos como universais, e justos para todos, a liberalização máxima propagada pela globalização e pelo neoliberalismo provocou reiteradas ondas de flexibilização dos direitos humanos (Santos, 1998) e dos direitos sociais. Na prática, estes direitos perderam efetividade, em especial os direitos trabalhistas, com muitos deles deixando de existir. 
Neste contexto neoliberal o novo papel do Estado seria garantir e proteger a ordem espontânea instituída pelo livre-mercado. A lógica é a de que com a diminuição do poder do Estado, as empresas transnacionais passam a assumir este poder, e a esfera pública deixa de tutelar os direitos sociais, fazendo com que eles gradualmente se dissipem (Lima, 2002) O agravante é que, conforme explica José Eduardo Faria, os direitos sociais dependem do Estado para serem instituídos e efetivados (Faria apud Lima, 2002).

O Estado-nação foi a dimensão espaço-temporal mais importante para o Direito nos últimos 200 anos. E isto porque as outras duas dimensões (local e transnacional) foram consideradas inexistentes pela teoria política liberal hegemônica (Santos, 1998).

Apesar disto, observa-se que outro aspecto jurídico, decorrente da globalização e do aumento da interdependência econômica dos Estados, é a diminuição do poder interno estatal, que passa a estar sujeito a centros de decisões externos e à permeabilidade de suas fronteiras (Lima, 2002, p. 206).

Neste contexto Boaventura de Sousa Santos (1998) aponta para os seguintes fatos:

1. que o campo jurídico nas sociedades contemporâneas e no sistema mundial como um todo compõe uma paisagem muito mais rica e complexa do que aquela assumida na teoria política liberal;

2. que este campo jurídico é uma constelação de legalidades (e ilegalidades) diversas, que operam em espaços e tempos locais, nacionais e transnacionais; e finalmente

3. que se se concebe desta forma, o Direito tem tanto um potencial regulatório ou repressivo, quanto um potencial emancipatório. 
Outro importante jurista português que destaca o pluralismo das fontes normativas do Direito é António Manuel Hespanha. Segundo este autor, a noção unitária do Estado e sua consideração como fonte exclusiva de produção das normas jurídicas já não é suficiente para explicar os mais recentes fenômenos sociais e jurídicos:

Hoje, tudo se tornou menos nítido e mais complexo. Ao Estado contrapõe-se uma sociedade que parece produzir normas diretamente sem necessitar da mediação oficial; à unidade do Estado contrapõe-se a dispersão de centros de poder normativos; às Nações, distintas e isoladas, contrapõe-se a "sociedade global" de todas as nações, ultrapassando as fronteiras dos Estados e pouco atenta ao recorte oficial das fronteiras; à unidade de cada um dos vários direitos, contrapõem-se direitos com diversos centros autônomos produtores de normas, desprovidos de coerência, sobrepostos, combinando normas de validade apenas local com outras que valem a um nível translocal, global. O Estado tende a deixar de ser considerado quer como a origem única do direito quer como a fonte de sua legitimação última (Hespanha, 2013, p. 18).

Diante deste cenário, outras fontes produtoras do Direito surgem, o que Hespanha chama de "Direito autêntico" (2013, p. 18), encontrado em lugares tais como na organização da vida corrente (famílias, regras comunitárias do convívio cotidiano), nas práticas estabelecidas ou nas inevitáveis leis dos negócios (as leis do mercado, a nova lex mercatoria), nas regras geralmente seguidas em certo setor de atividade (médicos, comunidade acadêmica ou científica), naquilo que é considerado correto em certo ramo de atividade (boas práticas da administração pública, da escola, nas relações entre uma organização e os seus usuários), e em inúmeros outros lugares (organizações representativas de um setor específico do trato social, Direito supraestadual, contratos privados, rotinas e usos comuns e assentes, os especialistas em Direito, etc.). 
Ainda que se reconheçam fontes múltiplas de normas, entretanto, isto não implica o reconhecimento automático de se tratar de Direito "sem mais averiguações, pois existe uma série de dúvidas a carecer de esclarecimento, quer quanto à sua jurisdicidade, quer quanto às hierarquias entre elas, em caso de contradição” (Hespanha, 2013, p. 61).

É neste sentido que o Direito, fruto da globalização e do neoliberalismo, deve passar por um crivo de validação jurídica, o que significa, sob a ótica da teoria pluralista revisada por Hespanha (2013), superar a avaliação empírica inicial de sua vigência adicionando a existência de consensos sociais alargados e adequados e que por isso sejam estáveis e estabilizadores.

Em outras palavras, a produção do Direito depende de uma validação democrática, que garanta a participação cidadã, ampla e diversificada. É exatamente este aspecto que deve ser avaliado quanto aos efeitos da globalização sobre o Direito das ordens jurídicas nacionais.

\section{O RETROCESSO AMBIENTAL}

Conforme visto, a globalização e o neoliberalismo estimulam a redução de direitos, a flexibilização de normas e, consequentemente, provocam retrocessos normativos. Importa caracterizar o retrocesso no Direito Ambiental brasileiro a partir de conceitos fundamentais e seus desdobramentos práticos na proteção do meio ambiente.

Por retrocesso entende-se o retorno a uma situação anterior considerada pior ou ultrapassada. Originário do latim retrocessus, este é o sentido apresentado pelo Dicionário Houaiss da Língua Portuguesa (2009, p. 1.661):

1. ato, processo ou efeito de retroceder, retrogradação, retrocessão - 2 . deslocamento físico para trás, retorno ao local de onde se saiu; retirada, recuo - 3. retorno no tempo; volta ao passado -4 . volta ao primitivo 
estado ou ordem, considerada ultrapassada em relação a uma determinada época (r. política) - 5. estado ou condição do que está começando a se degradar; decadência (grifos nossos).

Dessa forma, não é o simples retorno à situação anterior à atual que deve ser considerado um retrocesso, mas o fato de esse retorno ocorrer de maneira prejudicial, ultrapassada, gerando prejuízos sociais, políticos, econômicos e/ou ambientais. Observa-se nestes casos uma desconstrução ou inobservância do progresso já obtido, normalmente refletido no desenvolvimento de ações, institutos, instrumentos, políticas, programas, padrões de qualidade, etc.

O retorno sadio a uma situação anterior pode ser denominado de restauração, porém o retorno em sentido pejorativo, uma regressão, é o que caracteriza o retrocesso que se visa a evitar ou impedir a partir da construção deste princípio jurídico.

O Direito Ambiental brasileiro seguiu a tendência mundial e estabeleceu marcos legais avançados, especialmente a partir da Lei da Política Nacional do Meio Ambiente (Lei Federal $n^{\circ}$ 6.938/81) e do capítulo sobre Meio Ambiente na Constituição Federal de 1988.

Estes marcos legais constituíram aquilo o que parte da doutrina ${ }^{1}$ passou a denominar de microssistema jurídico de Direito Ambiental, ou seja, um conjunto coerente de normas, com princípios

\footnotetext{
${ }^{1}$ Sobre a caracterização do Direito Ambiental como microssistema jurídico vide: Nery Jr., Nelson. Código brasileiro de defesa do consumidor comentado pelos autores do anteprojeto. Rio de Janeiro: Forense Universitária, 1991. p. 272. Lorenzetti, Ricardo Luis. Fundamentos do direito privado. São Paulo: Revista dos Tribunais, p. 51, 1998; Antunes, Paulo de Bessa. Direito ambiental. 7. ed. Rio de Janeiro: Lumen Juris, 2004, p. 30; Prieur, Michel. Droit de l'environement. 4. ed. Paris: Dalloz, 2001, p. 6; Souza, Paulo Roberto Pereira de. A tutela jurisdicional do meio ambiente e seu grau de eficácia. In: Leite, José Rubens Morato; Dantas, Marcelo Buzagio (org.) Aspectos processuais do Direito Ambiental. Rio de Janeiro: Forense Universitária, 2003. p. 235.
} 
próprios e de base constitucional, que regulam uma situação fática específica, no caso a proteção ao meio ambiente ecologicamente equilibrado.

Diversas leis anteriores a 1988 foram recepcionadas e em sua grande maioria com aumento da relevância protetiva de seus dispositivos. As décadas seguintes também testemunharam o surgimento de diversas leis federais, tais como a criação do Sistema Nacional de Unidades de Conservação, a Política Nacional de Educação Ambiental, a Política Nacional de Recursos Hídricos, a Lei de Crimes Ambientais, a Política Nacional de Resíduos Sólidos e reformas no Código Florestal de 1965.

Apesar disto, os conflitos entre a proteção ambiental e o desenvolvimento econômico e social do Brasil nunca estiveram tão acirrados. Especialmente nos últimos anos observou-se um incremento significativo na renda de milhões de famílias brasileiras e o aumento do protagonismo internacional do país, gerando um aquecimento econômico que leva ao aumento do consumo, da produção industrial, da demanda por insumos e matérias-primas, de energia e, por fim, da geração de resíduos líquidos, gasosos e sólidos. $\mathrm{O}$ desenvolvimento brasileiro segue a tendência histórica mundial de aumentar significativamente a pressão sobre o meio ambiente, exigindo um reforço dos mecanismos de proteção ambiental, em especial os de natureza jurídica.

A reação de grande parcela de poluidores e prejudicados pelo enrijecimento da proteção do meio ambiente passou a ser articulada e nos últimos anos começou a ganhar corpo. Trata-se de um movimento de flexibilização normativa e administrativa, que pode resultar em uma verdadeira desconstrução do sistema jurídico-ambiental brasileiro como ele é conhecido hoje.

Diversos projetos de lei federal começaram a ser apresentados na última década no Congresso Nacional buscando privilegiar condutas e criar exceções às regras de proteção ambiental. Apesar disso, os proble- 
mas ambientais continuam se agravando, permitindo a conclusão de que os debates devem ser direcionados à revisão e melhoria contínua da legislação ambiental, e não ao seu simples retrocesso.

Por esta razão, reconhecer o princípio da proibição do retrocesso ambiental no Direito brasileiro é uma tarefa atual e urgente. O desafio é grande, pois a construção de um conceito jurídico de não retrocesso deve equilibrar-se com outros princípios fundamentais, com base na hermenêutica jurídica e não incorrer no erro pelo excesso no sentido contrário. A ordem jurídica é dinâmica e assim deve ser a produção e a interpretação normativa. Por outro lado, existem limites e marcos valorativos e naturais que devem ser respeitados. Identificar e explicitar estes limites é o desafio desta pesquisa, que contribuirá para a conceituação de retrocesso ambiental e apontará fundamentos jurídicos para o impedimento de ataques descabidos aos valores e alicerces do Estado de Direito Ambiental Brasileiro.

Quando o retrocesso ambiental estiver em jogo a questão que se coloca é se uma geração humana tem o direito de impedir a vida com qualidade de outra geração e de que maneira os mais modernos sistemas democráticos seriam capazes de validar uma decisão desta natureza. A crise ambiental e o princípio da proibição do retrocesso ambiental destroem a máxima intergeracional criada a partir da Revolução Francesa, conforme explica Pietro Costa (2010), estabelecendo que cada geração possui o direito de, partindo do zero, reinventar o futuro. Esta noção ficou consagrada na constituição jacobina de 1793 (artigo 28) que prescreve: "Uma geração não pode sujeitar às suas leis as gerações futuras”.

Ainda não há consenso quanto à terminologia empregada hoje para expressar o princípio da proibição do retrocesso ambiental, que também recebe as seguintes denominações: (a) princípio do standstill no Direito belga; (b) "efeito catraca" ou "regra catraca antirretorno" na doutrina francesa; (c) intangibilidade dos direitos fundamentais, para Olivier de Frouville; (d) direitos legislativos adquiridos ou a irreversibilidade dos direitos 
humanos, para Konrad Hesse; (e) a cláusula do status quo ou de proibição da retrogressão, para S. R. Osmani. Em inglês existe a expressão ratchet principle, em espanhol prohibicion de regressividad o de retrocesso; e em português “proibição de retrocesso" (Prieur; Sozzo, 2012, p. 8).

Para Michel Prieur (In: Prieur; Sozzo, 2012a, p. 8), o melhor ainda é optar pela expressão "princípio de não retrocesso" (principe de non régression) por ela "bem demonstrar que o que está em jogo é a salvaguarda do progresso adquirido no conteúdo da legislação ambiental”. Neste sentido, o autor explica que até se poderia utilizar a terminologia "princípio do progresso”, mas ele é muito vago e na prática toda a legislação pressupõe garantir o progresso da sociedade. Além disso, explica o autor que o objetivo é destacar a especificidade do Direito Ambiental quanto aos recuos que constituem retrocesso na proteção do meio ambiente, mesmo quando estes não sejam absolutos, mas apenas gradações da regressão.

O autor brasileiro Carlos Molinaro (2007, p. 67) defende a noção da proibição da retrogradação ambiental, pois “a vedação da degradação ambiental constitui-se no objeto do princípio da proibição da retrogradação socioambiental em sede de direito ambiental" e também que "retrogradar expressa melhor a ideia de retroceder". E continua o professor: “o que o direito ambiental objetiva é proteger, promover e evitar a degradação do ambiente”.

O Direito Ambiental manifesta em suas normas e objetivos um caráter finalista de progresso e desenvolvimento sustentável. Esta é a lógica defendida por Michel Prieur e Gonzalo Sozzo. Para o autor francês, "o objetivo do Direito Ambiental é de lutar contra a poluição e preservar a biodiversidade” (In: Prieur; Sozzo, 2012a, p. 9) Em outras palavras, “aquele que devido a seu conteúdo contribui para a saúde pública e à manutenção do equilíbrio ecológico integra o Direito Ambiental” (In: Prieur; Sozzo, 2012a, p. 10). 
Para Gonzalo Sozzo (In: Prieur; Sozzo, 2012, p. 73), a finalidade assume o caráter de um progresso como "perdurabilidade”, o que leva a uma permanência transgeracional. Segundo este autor, "é necessário sermos mais radicais. Que a fundação do princípio da proibição do retrocesso exige uma base teórica mais ousada, mais universal, mais cosmopolita. Esta base é a ideia do progresso como perdurabilidade”.

Segundo o autor argentino, a partir da segunda modernidade o futuro deixa de ser visto como progresso e começa a ser visualizado como duração, surgindo uma nova metáfora para se referir ao futuro: as gerações futuras. (In: Prieur; Sozzo, 2012, p. 73). Assim observa-se uma nova transformação da noção de progresso: como "perdurabilidade”, o que nas palavras do autor "implica admitir que se progride quando se assegura as gerações futuras a transmissão de um certo volume de bens e o progresso como perdurável, não durável” (In: Prieur; Sozzo, 2012, p. 74).

Observe-se que o direito ao meio ambiente ecologicamente equilibrado, juntamente com a noção de preservação dos processos ecológicos essenciais, indicam marcos ou limites mínimos para a proteção ambiental, mas mais do que isto, criam feixes complexos de direitos humanos e deveres constitucionais interligados a partir da finalidade mediata desta proteção, qual seja, a promoção da qualidade de vida. Na prática, podem existir retrocessos ambientais que não impliquem necessariamente a degradação ambiental, razão pela qual a opção pela denominação "proibição do retrocesso ambiental" ainda se mostra mais abrangente e adequada.

Para Ingo Sarlet (2009, p. 4), ${ }^{2}$ considera-se o retrocesso uma situação constitucionalmente ilegítima que se configura “[...] quando forem transpostas certas barreiras, representadas, por sua vez, por um conjunto

${ }^{2}$ Coletânea especial dos artigos relativos às palestras apresentadas no $20^{\circ}$ Encontro Regional da Amatra, em Buenos Aires, nos dias 11 e 12 de junho de 2009. Disponível em: <http:// www.amatra4.org.br/cadernos/263-caderno-13?start=3>. Acesso em: 15 dez. 2011. 
de limites expressos e implícitos estabelecidos pela ordem jurídico-constitucional, sem prejuízo de barreiras inerentes ao processo político e social, em geral mais eficazes quando se trata de conter determinadas reformas”.

José Gomes Canotilho (2001, p. 337) reconhece não ser possível fazer frente à reversibilidade fática, tal como em recessões ou crises econômicas, porém entende que o princípio da proibição do retrocesso (no caso analisado no âmbito social) "[...] limita a reversibilidade dos direitos adquiridos, em clara violação do princípio da protecção da confiança e da segurança dos cidadãos no âmbito econômico, social e cultural, e do núcleo essencial da existência mínima inerente ao respeito pela dignidade da pessoa humana" (grifos do autor).

Outra questão recorrente é a da defesa da soberania dos parlamentos ante o direito adquirido das leis postas. Nestes casos observa-se que $o$ excesso de poder Legislativo choca-se contra a busca da equidade ambiental. Argumentar que a proibição do retrocesso dos direitos ambientais implicaria o engessamento legislativo ou mesmo o desrespeito ao papel e soberania desse poder é um equívoco. Dessa forma, fundamental será o reconhecimento de claros e seguros indicadores da Constituição Federal e dos princípios fundamentais do ordenamento jurídico que apontem para os limites às mudanças legais e administrativas.

É neste sentido que Éric Naim-Gesbert explica que “o princípio da proibição do retrocesso significa o não-retorno sobre o acervo jurídico contra ventos e mares - e uma concepção aberta à adaptação da norma” (In: Prieur; Sozzo, 2012, p. 126). Busca assim mostrar que o princípio não induz à imutabilidade, mas apenas estabelece um nível de proteção que não pode ser reduzido, seja material ou processualmente, de tal sorte que a modificação de uma norma que regule direitos fundamentais deve apresentar soluções no mínimo equivalentes em termos de resultados, demonstrando o caráter finalista do Direito Ambiental. 


\section{A GLOBALIZAÇÃO DO DIREITO, O NEOLIBERALISMO E O RETROCESSO NO DIREITO AMBIENTAL BRASILEIRO}

A História da humanidade está permeada por movimentos ou ondas de progresso e retrocesso. As grandes guerras, pestes e ditaduras, por exemplo, foram capazes de destruir em pouco tempo conquistas civilizatórias que levaram centenas de anos para serem produzidas. Apesar disto, de maneira geral é possível observar uma curva ascendente do aprimoramento da vida humana em decorrência destas conquistas civilizacionais.

Talvez a grande novidade trazida pelo mais moderno conceito de globalização econômica e sua fundamentação ideológica no neoliberalismo, esteja na velocidade com que retrocessos podem ocorrer. A atual estrutura global da economia, do Direito e da política permitem transformações em sistemas governamentais, empresariais e normativos com uma velocidade impressionante.

As consequências ultrapassam as fronteiras da acumulação e emprego do capital, das forças de trabalho e alcançam a cultura de diferentes povos, submetidos a valores e ideologias uniformizadoras, subordinantes e que produzem hordas apáticas de cidadãos desvinculados da política, uma vez que impedidos de se manifestar ou porque sua participação é considerada irrelevante.

Boanventura de Sousa Santos destaca o caráter paradoxal deste momento da humanidade, pois se de um lado observa-se grandes avanços e transformações, "dramaticamente designadas por revolução da informação e da comunicação, revolução eletrônica, revolução da genética e da biotecnologia”, por outro lado destaca se tratar de:

[...] um tempo de inquietantes regressões, do regresso de males sociais que pareciam superados ou em vias de o ser: o regresso da escravatura e do trabalho servil; o regresso da alta vulnerabilidade a doenças 
antigas que pareciam erradicadas, pelo menos nos países mais desenvolvidos, como a tuberculose, e a doenças novas de proporções pandêmicas, como o HIV/Aids; o regresso das repugnantes desigualdades sociais que deram nome à questão social no final do século XIX; enfim, o regresso do espectro da guerra, talvez agora mais mundial que nunca e com uma temperatura (quente? fria?), por agora ainda indefinível (Santos, 2002, p. 130).

No âmbito do Direito Ambiental, Michel Prieur e Gonzalo Sozzo (Prieur; Sozzo, 2012), destacam duas principais ameaças ao recuo normativo:

1. a. políticas: a vontade demagógica de simplificar o Direito por meio da desregulação, em virtude do grande número de normas jurídicas ambientais tanto no plano internacional quanto nacional;

2. b. econômicas: a crise econômica mundial favorece o discurso que exige menos obrigações jurídicas no domínio ambiental, pois constituiriam um freio ao desenvolvimento e à erradicação da pobreza.

Aí surge o princípio da proibição do retrocesso como tentativa de minimizar os efeitos jurídicos da globalização, ao impor uma proibição da piora dos níveis de proteção jurídica já alcançada por um determinado Direito fundamental. Esta lógica, há tempo discutida para os direitos sociais, agora também chega ao Direito Ambiental com maior ênfase, particularmente pelo aumento da pressão legislativa em todo o mundo por retrocessos ambientais. 
Para melhor compreensão deste cenário, interessante analisar o recente caso da aprovação do "novo" Código Florestal brasileiro no Congresso Nacional, ${ }^{3}$ que revela um enfraquecimento dos institutos jurídicos ambientais, em flagrante choque com as garantias constitucionais (especialmente o artigo 225, CF). Trata-se de um claro exemplo de retrocesso em matéria ambiental, provocada pelo próprio Estado brasileiro, no seio de seu poder parlamentar, e cujas causas apontam tanto para a incapacidade técnica dos parlamentares, bem como para sua falta de sensibilidade para com as questões importantes de seu tempo, assim como pela fortíssima influência de grandes transnacionais do setor de agronegócios que enxergam nas normas de proteção florestal verdadeiras barreiras ao crescimento de seus campos de produção e, naturalmente, de seus lucros.

Observa-se assim que enquanto hábil para tutelar os interesses de grandes corporações, o Direito é utilizado, mantido e preservado. Este é o caso de uma série de normas relativas ao crédito agrícola, às isenções tributárias e inclusive à inadmissível anistia de multas e outras sanções administrativas contra desmatadores no Brasil, promovidas pelo novo texto legal florestal.

Por outro lado, quando a norma jurídica cria obstáculos a interesses econômicos, a velocidade e capacidade de alteração das leis mostra-se inacreditável, deixando perplexos os poucos cidadãos críticos que restaram em uma sociedade apática e indiferente. Mesmo diante de tantos argumentos contrários tornados públicos, e de um forte movimento ambientalista por meio de ONGs e campanhas públicas, o projeto final acabou aprovado.

\footnotetext{
${ }^{3}$ Trata-se do projeto de Lei $\mathrm{n}^{\circ}$ 1.876-E/99 que, após aprovação polêmica e controvertida no Congresso Nacional, alterou o Código Florestal Brasileiro, podendo ser considerado um exemplo recente de grande e sério retrocesso ambiental, sob diversos aspectos. Duarte, Geiza. Código Florestal é aprovado na Câmara dos Deputados - Para ambientalistas, texto é um retrocesso na defesa do meio ambiente. Jornal da Globo. 26/4/2012. Disponível em: $<$ http://g1.globo.com/jornal-da-globo/noticia/2012/04/codigo-florestal-e-aprovado-nacamara-dos-deputados.html>. Acesso em: 3 maio 2012.
} 
Em primeiro lugar, o novo texto propõe uma série de abrandamentos das exigências de preservação florestal, diminuindo a extensão e obrigatoriedade da reserva legal e das áreas de preservação permanente. ${ }^{4}$ Ao mesmo tempo, o país passa pela ampliação das áreas desmatadas (Carvalho, 2011), aumento este estimado em mais de $127 \%$ nos últimos dez anos nas áreas de proteção e uma condição de déficit de áreas verdes nativas por habitante, considerando-se o índice recomendado pela Organização Mundial da Saúde (Campello, 2008).

Nitidamente, os aspectos técnicos e científicos relativos ao papel das florestas para o equilíbrio ecológico estão sendo ignorados e abafados pelos parlamentares (Oliveira, 2011) defensores do novo Código e do retrocesso que ele representa para a proteção ambiental.

Merece atenção não apenas o texto final aprovado pela Câmara Federal no segundo turno, ${ }^{5}$ mas todo o percurso que o projeto passou por diversos turnos em ambas as Casas Legislativas e a polêmica e desacordos que ainda gerou nas revisões da Medida Provisória que se tornou

\footnotetext{
${ }^{4}$ As margens dos rios passam a ter a APP medida a partir do leito regular e não do leito maior. Além disto, para os rios com até 10 metros de largura, a APP deixou de ser de $30 \mathrm{~m}$ para apenas $15 \mathrm{~m}$. Outro ponto aprovado permite o uso das áreas de preservação permanente (APPs) já ocupadas com atividades agrossilvipastoris, ecoturismo e turismo rural, desde que o desmatamento até então ilegal tenha ocorrido até 22 de julho de 2008. Em relação à Reserva Legal, o texto recebido pelo Senado prevê isenção da obrigação de recomposição para os "pequenos produtores", definidos como aqueles que possuem propriedade de até 4 (quatro) módulos fiscais - o módulo fiscal varia de 5 (cinco) a 100 (cem) hectares, a depender da região. O texto aprovado na Câmara também prevê uma anistia geral para os responsáveis por desmatamentos ilegais realizados até 22 de julho de 2008, desde que o até então infrator adira ao Programa de Regularização Ambiental (PRA). (Maia Neto, Geraldo Azevedo. In Jus Navigandi. Novo Código Florestal: os principais pontos do projeto aprovado pela Câmara dos Deputados, as possíveis alterações no Senado Federal e o poder de veto presidencial. Disponível em: $<$ http://jus.com.br/revista/ texto/20023/novo-codigo-florestal-os-principais-pontos-do-projeto-aprovado-pela-camarados-deputados-as-possiveis-alteracoes-no-senado-federal-e-o-poder-de-veto-presidencial>. Acesso em: 8 nov. 2011).

${ }^{5}$ Projeto de Lei 1/876-E/99. Texto integral, disponível em: <http://www.camara.gov.br/ proposicoesWeb/prop_mostrarintegra;jsessionid=5D26B1190359200D1A49CFFB51107409. node2 ?codteor=987261\&filename=Tramitacao-PL+1876/1999>. Acesso em: 3 maio 2012.
} 
necessária devido ao veto da Presidência da República de alguns artigos. Em cada Casa Legislativa e em cada um destes momentos, concessões, pressões e acordos políticos (e não técnicos) possibilitaram construções legais que configuraram retrocessos ambientais.

Num caso como este em que o próprio poder Legislativo é incapaz de entrar em consenso sobre o conflito entre direitos e promover uma série de alterações legais que configuram retrocessos ambientais ou, em outras palavras, afrontes a direitos fundamentais garantidos pela Constituição Federal, como evitar que outra instância, no caso o poder Judiciário, não se envolva ou assuma um papel decisivo para a salvaguarda do Estado Democrático de Direito?

Esta é uma das justificativas da atuação da Procuradoria Geral da República com a propositura de três ações diretas de inconstitucionalidade (Adins 4.901 - ministro Luiz Fux, 4.902 - ministra Rosa Weber e 4.903 - ministro Gilmar Mendes), em janeiro de 2013, contra o novo texto do Código Florestal. ${ }^{6}$ Um dos argumentos centrais das Adins, em especial a 4.902 , está exatamente no princípio da proibição de retrocesso socioambiental.

A propositura desta ações, em parte esperada por grande parcela da sociedade brasileira, é um exemplo vivo e recente de um processo democrático ainda vulnerável e imaturo no Brasil. Diante da imensa dificuldade do processo deliberativo parlamentar, que se mostrou despreparado e incapaz de liderar grandes debates sobre os desafios ambientais para o desenvolvimento do país, a questão retorna ao poder Judiciário. A partir destes fatos, é reforçada a figura de um Judiciário que se identifica cada vez mais com a "última palavra” ou a "decisão definitiva e final” sobre quaisquer temas de interesse nacional.

${ }_{6}^{6}$ Disponível em: <http://veja.abril.com.br/noticia/brasil/pgr-questiona-constitucionalidadedo-codigo-florestal>. Acesso em: 5 mar. 2013. 
Em caráter pioneiro, a decisão do Superior Tribunal de Justiça sob a relatoria do ministro Antônio Herman Benjamin no Resp. $n^{0}$ 302.906/ SP (Brasil, STJ, 2011) trouxe à tona a aplicação do princípio da proibição do retrocesso ambiental em um caso envolvendo questões urbanístico-ambientais. ${ }^{7}$

Observa-se a tentativa do julgador em estabelecer critérios que permitam identificar os limites a partir dos quais se observa uma regressão, mas principalmente, em estabelecer que a presunção é sempre a de tornar exceção a condição do abrandamento ou retrocesso das leis, de acordo com o ius variandi próprio do poder público.

Em seu voto, o ministro Antônio Herman Benjamin ressalta a importância da motivação por parte do poder público que permita o afrouxamento da legislação ambiental ou urbanística:

Em linha de princípio - princípio inescapável -, o Estado só está autorizado a flexibilizar restrições urbanístico-ambientais convencionais na presença de inequívoco interesse público, incapaz de ser atendido por outra via ou mecanismo menos gravoso à coletividade de vizinhos, jamais para satisfazer interesses políticos de momento, contingências eleitorais, arroubos populistas, objetivos imediatistas, ou para se curvar a demandas da febre insaciável da especulação imobiliária.

\footnotetext{
7 PROCESSUAL CIVIL, ADMINISTRATIVO, AMBIENTAL E URBANÍSTICO. LOTEAMENTO CITY LAPA. AÇÃO CIVIL PÚBLICA. AÇÃO DE NUNCIAÇÃO DE OBRA NOVA. RESTRIÇÕES URBANÍSTICO-AMBIENTAIS CONVENCIONAIS ESTABELECIDAS PELO LOTEADOR. ESTIPULAÇÃO CONTRATUAL EM FAVOR DE TERCEIRO, DE NATUREZA PROPTER REM. DESCUMPRIMENTO. PRÉDIO DE NOVE ANDARES, EM ÁREA ONDE SÓ SE ADMITEM RESIDÊNCIAS UNI FAMILIARES. PEDIDO DE DEMOLIÇÃO. VÍCIO DE LEGALIDADE E DE LEGITIMIDADE DO ALVARÁ. IUS VARIANDI ATRIBUÍDO AO MUNICÍPIO. INCIDÊNCIA DO PRINCÍPIO DA NÃO-REGRESSÃO (OU DA PROIBIČ̃̃O DE RETROCESSO) URBANÍSTICOAMBIENTAL. VIOLAÇÃO AO ART. 26, VII, DA LEI 6.766/79 (LEI LEHMANN), AO ART. 572 DO CÓDIGO CIVIL DE 1916 (ART. 1.299 DO CÓDIGO CIVIL DE 2002) E À LEGISLAÇÃO MUNICIPAL. ART. 334, I, DO CÓDIGO DE PROCESSO CIVIL. VOTOMÉRITO. (grifo nosso) (Brasil, 2011).
} 
Vale dizer, o legislador pode, sim, abrandar as exigências urbanístico-ambientais convencionais. No entanto, ao contrário do amplo poder de intervenção que the confere a ordem constitucional e legal vigente para aumentar seu rigor, ao reduzi-lo só poderá fazê-lo em circunstâncias excepcionais e de maneira cabalmente motivada. Essa regra geral, aplicável ao Direito Urbanístico (em sintonia com igual fenômeno no Direito Ambiental), é decorrência da crescente escassez de espaços verdes e dilapidação da qualidade de vida nas cidades e submete-se ao princípio da não-regressão (ou, por outra terminologia, princípio da proibição de retrocesso), garantia de que os avanços urbanístico-ambientais conquistados no passado não serão destruídos ou negados pela geração atual (Brasil, 2011) (grifos nossos).

Nesta linha de argumentação, observa-se que o direito ao meio ambiente, de natureza reconhecidamente difusa, apresenta uma característica fundamental: a intensa litigiosidade interna. De origem italiana, este conceito foi trazido ao Brasil pelo jurista Rodolfo de Camargo Mancuso (Mancuso, 2004). De acordo com este autor, quanto aos conflitos que se originam da defesa de interesses ou direitos difusos, “[...] não se trata de controvérsias envolvendo situações jurídicas definidas [...], mas de litígios que têm por causa remota verdadeiras escolhas políticas. Ora, neste campo, as alternativas são ilimitadas” (Mancuso, 2004, p. 101).

Por isto é possível que questões envolvendo a proteção ambiental sejam revistas e alteradas com frequência, mesmo nos casos mais difíceis e que tenham obtido consagração judicial máxima. $\mathrm{O}$ fechamento da "Estrada do Colono" no Parque Nacional do Iguaçu é um exemplo. Mesmo após décadas de disputa judicial, que culminou com a consagração da decisão da Justiça Federal pelo total fechamento da estrada, inclusive com intervenções da Polícia Federal para conter manifestantes contrários à decisão, o assunto retorna às discussões públicas, amparada por um 
deputado federal e um grupo de políticos apoiadores. ${ }^{8}$ Não é de se estranhar que membros do Executivo, de órgãos ambientais e mesmo do poder Judiciário defendam a reabertura da estrada: existem interesses legítimos de parcela da população (Baptiston; Garcia, 2013).

A questão-chave nestes casos é saber se existe de fato um limite, ou critérios que permitam a tomada de uma decisão. Para Rodolfo de Camargo Mancuso (2004, p. 103):

Não se cuidando de direitos violados ou ameaçados, mas de interesses (conquanto relevantes), tem-se que nesse nível, todas as posições, por mais contrastantes, parecem sustentáveis. É que nesses casos de interesses difusos não há um parâmetro jurídico que permita um julgamento axiológico preliminar sobre a posição "certa" ou "errada".

Apesar de aparentemente defensável sob o ponto de vista lógico, esta posição também apresenta falhas. Especificamente no contexto da proteção ambiental, o Direito passou a ser balizado por um conjunto normativo de base predominantemente axiológica. Além de informarem valores fundamentais, estas normas também conectam o Direito com outras

\footnotetext{
${ }^{8}$ Conforme relatado pela mídia, cerca de 400 pessoas participaram no dia 25 de novembro de 2011 da audiência pública realizada na Casa da Cultura de Capanema, no Sudoeste do Paraná, para debater o projeto de Lei do deputado federal Assis do Couto (PT) criando a Estrada-Parque “Caminho do Colono" (Projeto n⿳ำ 7123/2010), trecho de 17,5 quilômetros que corta o Parque Nacional do Iguaçu e que se encontra sob interdição judicial desde 1986 (Fernandes, Julio Cesar. Aqui Sudoeste Online. Cidades. Em Capanema, moradores intensificam defesa da estrada-parque. 28/11/2011. Disponível em: <http://www. aquisudoeste.com.br/CIDADES/em_capanema_moradores_intensificam_defesa_da_ estrada_parque,9100.html $>$. Acesso em: 28 nov. 2011. Outras reportagens sobre a proposta: http://www.liberalonline.com.br/index.php?option=com_content\&view=article\&id=1262: moradores-reivindicam-criacao-da-estrada-parque-caminho-do-colono\&catid=40:politica\&I temid=59> e < http://www.oeco.com.br/maria-tereza-jorge-padua-lista/25460-estrada-docolono-tesoura-que-parte-iguacu-pela-metade>.)
} 
áreas do conhecimento, tais como a Ecologia, a Biologia e a Ética. ${ }^{9}$ E estes valores estão expressos em princípios jurídicos integrados ao texto e à interpretação constitucional.

É justamente a partir de sua base axiológica que o Direito Ambiental apresenta a proibição do retrocesso ambiental como limite ou barreira para a manutenção de propostas ou projetos de reformulação de leis ou parâmetros legais de proteção ambiental. Mesmo encontrando-se legitimidade nos argumentos dos que defendem a alteração legislativa, por exemplo, no caso dos moradores isolados pelo fechamento da "Estrada do Colono" no Parque Nacional do Iguaçu, o fato de que a reabertura desta estrada provocará danos irreparáveis para o ecossistema protegido por um sistema federal e constitucional de preservação ambiental, impede o retorno ao status quo anterior. Isto porque, neste caso, configura-se o retrocesso ambiental, de natureza nociva e indesejável. Este tipo de decisão não pode mais ficar sujeita meramente aos cuidados da discricionariedade política, mas sim de parâmetros técnicos, constitucionais e axiológicos prevalecentes. Não se trata de encontrar a posição mais forte, mais numerosa ou mais simpática, mas sim, de fazer prevalecer um pressuposto já identificado pela ciência como necessário à conservação da vida e do equilíbrio ecológico - ambos valores já consagrados em nossa sociedade como fundamentais.

Esta mesma discussão é ampliada quando os fatores da globalização e do neoliberalismo aceleram e ampliam os efeitos prejudiciais para a população subjugada e a sanidade de todo o planeta. Com a despersonalização que acompanha as transnacionais, decisões localizadas, em restritos centros de concentração de poderes, levam a transformações retrógradas na vida de milhões de pessoas.

${ }_{9}^{9}$ Vide Moreno, José Luis Serrano. Ecologia y Derecho: principios de Decrecho Ambiental y Ecología Jurídica. 2. ed. Granada: Ecorama, 1992. 
Nestes casos, a questão a ser respondida diz respeito a qual carga de legitimidade carregam estas decisões, que promovem o desenvolvimento econômico, a massificação da economia, a eficiência tecnológica da produção, o uso intenso e implacável dos recursos naturais, em detrimento da qualidade de vida, da dignidade humana, da solidariedade e tantos outros valores reconhecidos como superiores por diferentes culturas e tempos históricos.

Como exemplifica a coletânea de casos organizada por Boaventura de Sousa Santos ainda em 2002, apesar de hegemônica, a forma de globalização predominante não é a única e tem sido confrontada por uma outra forma de globalização, que nas palavras do autor é “[...] uma globalização alternativa, contra-hegemônica, constituída por um conjunto de iniciativas, movimentos e organizações que, através de vínculos, redes e alianças locais/globais, lutam contra a globalização neoliberal mobilizados pela aspiração de um mundo melhor, mais justo e pacífico que julgam possível e ao qual sentem ter direito" (Santos, 2002, p. 15).

Mesmo estas iniciativas propositivas de novos caminhos de emancipação social (Santos, 2002), contudo, dependem, se submetem e criam o direito. E neste sentido, também estão sujeitas ao retrocesso normativo, especialmente nos constantes embates com os cânones da globalização hegemônica. Por essa razão, o reconhecimento da proibição do retrocesso ambiental, fundado em sua essência no reconhecimento de um direito fundamental à vida com qualidade e ao ambiente ecologicamente equilibrado surge como um importante instrumento assegurador da sobrevivência da espécie humana.

\section{CONCLUSÕES}

O mundo está dominado pelas ideias inspiradas ou decorrentes das diretrizes neoliberais e assiste os efeitos nocivos da globalização econômica sobre diversas dimensões. 
Um dos campos mais atacados é o meio ambiente e todos os esforços normativos de proteção ambiental passaram a estar também na mira das ações de desregulação de direitos fundamentais.

Mesmo outras formas de globalização ligadas a movimentos que buscam a emancipação social também estão sujeitas às ações que configuram retrocessos normativos ambientais.

Esse fator provoca a necessidade urgente do reconhecimento do princípio da proibição do retrocesso ambiental, com destaque para o Direito brasileiro, o que tem início com algumas discussões doutrinárias e uma primeira decisão do STJ.

Um caso emblemático de retrocesso normativo ambiental é a recente aprovação do Novo Código Florestal Brasileiro, que apresenta inúmeros exemplos de retrocessos ambientais. Sua aprovação foi liderada especialmente por defensores do agronegócio, sustentada por grandes transnacionais.

O debate no Congresso Nacional demonstrou que argumentos científicos, tentativas de harmonização dos interesses sociais, ambientais e econômicos e a participação pública foram ignorados e atropelados pelo lobby dos agronegócios.

Diante disto, o último front está agora para ser testado. Com a propositura de três ações diretas de inconstitucionalidade contra o novo Código Florestal Brasileiro, o Ministério Público Federal coloca à prova a capacidade do Supremo Tribunal Federal de efetivamente defender os limites mínimos de existência com qualidade e de preservação do equilíbrio ecológico. A dúvida é: Se milhões de brasileiros, tornados consumidores, já foram submetidos, se centenas de parlamentares já foram convencidos, será que 11 ministros sobreviverão? 


\section{REFERÊNCIAS}

AMIRANTE, Domenico. Le principe de non régression de l'environnement en droit italien. In: PRIEUR, Michel; SOZZO, Gonzalo (Org.). La non régression en droit de l'environnement. Bruxelas: Bruylant, 2012. p. 333-346.

ARAGÃO, Alexandra. Le fondement européen de la prohibition de régression: le niveau élevé de protection de l'environnement. In: PRIEUR, Michel; SOZZO, Gonzalo (Org.). La non régression en droit de l'environnement. Bruxelas: Bruylant, 2012. p. 347-364.

BAPTISTON, Kalina Ribeiro; GARCIA, Júlio César. Análise do projeto de lei 7.123/2010 "Estrada Parque Caminhos do Colono" à luz do princípio da proibição do retrocesso ambiental. In: CONGRESSO NACIONAL DO CONPEDI: Sociedade global e seus impactos sobre o estudo e a efetividade do direito na contemporaneidade, 12. Florianópolis: Funjab, 2013. Disponível em: <www. conpedi.org.br>.

BORN, Charles-Hubert. Le principe de non régression en droit de l'environnement - la situation en Belgique. In: PRIEUR, Michel; SOZZO, Gonzalo (Org.). La non régression en droit de l'environnement. Bruxelas: Bruylant, 2012. p. 285-306.

BRASIL. STJ. REsp 302906 / SP, Recurso Especial 2001/0014094-7, Relator Ministro Herman Benjamin, Segunda Turma, DJ 26/08/2010, DP 01/12/2010. Disponível em: <www.stj.jus.br>. Acesso em: 25 nov. 2011.

CAMPELLO, Célio da Cunha. Áreas verdes: índices que sustentam a vida. Portal do Ministério Público do Estado de São Paulo. 2008. Disponível em: $<$ http://www.mp.sp.gov.br/portal/page/portal/cao_urbanismo_e_meio_ ambiente/material_apoio/mamodelos/mod_urbanismo/mod_urb_pecas/ mod_urb_pecas_parecer/ÁREAS-VERDES-ÍNDICES-QUE-SUSTENTAM-A-VIDA.pdf>. Acesso em: 8 nov. 2011.

CANOTILHO, J. J. Gomes. Direito Constitucional e Teoria da Constituição. 5. ed. Coimbra: Almedina, 2001. 
CARVALHO, Cleide. Desmatamento aumentou 127\% em áreas de proteção ambiental nos últimos dez anos. In $O$ Globo, 6/10/2011. Disponível em: <http://oglobo.globo.com/pais/mat/2011/10/06/desmatamento-aumentou-127-em-areas-de-protecao-nos-ultimos-dez-anos-925531398.asp>. Acesso em: 8 nov. 2011.

CHOMSKY, Noam. Ou o lucro ou as pessoas. Rio de Janeiro: Bertrand Brasil, 2002.

COSTA, Pietro. Democracia política e Estado constitucional. In: COSTA, Pietro. Soberania, representação, democracia: ensaios de história do pensamento jurídico. Curitiba: Juruá, 2010, p. 241-274.

GARCIA, Júlio César. A multidimensionalidade do bem ambiental e o processo civil coletivo brasileiro. In: Revista de Direito Ambiental, São Paulo: RT, n. 37, p. 110-137, 2004.

HACHEZ, Isabelle. Le principe de standstill dans le droit des droits fondamentaux: une irréversibilité relative. Bruxelles: Bruylant, 2008.

HESPANHA, António Manuel. Pluralismo jurídico e direito democrático. São Paulo: Annablume, 2013.

HERVÉ-FOURNERAU, Nathalie. Le principe de non régression environementale, en doit de l'Union Européenne: entre idéalité et réalité normative? In: PRIEUR, Michel; SOZZO, Gonzalo. (Org.). La non régression en droit de l'environnement. Bruxelas: Bruylant, 2012. p. 197-220.

HOUAISS, Antônio. Dicionário Houaiss da língua portuguesa. 1. ed. Rio de Janeiro: Objetiva, 2009.

LIMA, Abili Lázaro Castro de. Globalização econômica, política e direito: análise das mazelas causadas no plano político-jurídico. Porto Alegre: Sergio Antonio Fabris Editor, 2002.

MANCUSO, Rodolfo de Camargo. Interesses difusos. 6. ed. São Paulo: RT, 2004. MAIA NETO, Geraldo Azevedo. In: Jus Navigandi. Novo Código Florestal: os principais pontos do projeto aprovado pela Câmara dos Deputados, as possíveis alterações no Senado Federal e o poder de veto presidencial. Disponível 
em: <http://jus.com.br/revista/texto/20023/novo-codigo-florestal-os-principais-pontos-do-projeto-aprovado-pela-camara-dos-deputados-as-possiveis-alteracoes-no-senado-federal-e-o-poder-de-veto-presidencial>. Acesso em: 8 nov. 2011.

MOLINARO, Carlos Alberto. Direito ambiental: proibição de retrocesso. Porto Alegre: Livraria do Advogado, 2007.

MORENO, José Luis Serrano. Ecologia y Derecho: principios de Derecho Ambiental y Ecología Jurídica. 2. ed. Granada: Ecorama, 1992.

NAIM-GESBERT, Éric. La Science et le Principe de Non-Retour sur l'Acquis Juridique. In: PRIEUR, Michel; SOZZO, Gonzalo (Org.). La non régression en droit de l'environnement. Bruxelas: Bruylant, 2012.

OLIVEIRA, Marina. Cientistas pedem adiamento da votação do novo Código Florestal. In: G1, Política, 25/04/11. Disponível em: <http://g1.globo.com/ politica/noticia/2011/04/cientistas-pedem-adiamento-da-votacao-do-novo-codigo-florestal.html>. Acesso em: 8 nov. 2011.

PRIEUR, Michel. Le Nouveau Principe de “Non Régression” en Droit de L'environnement. In: PRIEUR, Michel; SOZZO, Gonzalo (Org.). La non régression en droit de l'environnement. Bruxelas: Bruylant, 2012a.

. Princípio da proibição de retrocesso ambiental. In: SENADO FEDERAL; COMISSÃO DE MEIO AMBIENTE, DEFESA DO CONSUMIDOR E FISCALIZAÇÃO E CONTROLE. Coletânea do Colóquio O Princípio da Proibição de Retrocesso Ambiental. Brasília-DF, 2012b. p. 40.

SANTOS, Boaventura de Sousa. La globalización del derecho. Los nuevos caminos de la regulación y la emancipación. Bogotá: Ilsa, 1998.

(Org.). Produzir para viver: os caminhos da produção não capitalista. Rio de Janeiro: Civilização Brasileira, 2002.

SARLET, Ingo Wolfgang. O Estado social de direito, a proibição de retrocesso e a garantia fundamental da propriedade. In: Revista da Faculdade de Direito da UFRGS, n. 17, p. 111-132, 1999. 
A eficácia dos direitos fundamentais. 9. ed. Porto Alegre: Livraria do Advogado, 2008.

Algumas notas a respeito dos direitos fundamentais sociais e a proibição de retrocesso: desafios e perspectivas. In: Cadernos da Amatra IV, n. 13, coletânea especial dos artigos relativos às palestras apresentadas no XX Encontro Regional da Amatra, em Buenos Aires, nos dias 11 e 12 de junho de 2009, p. 4. Disponível em: <http://www.amatra4.org.br/cadernos/263-caderno-13?start=3>. Acesso em: 15 dez. 2011.

SOZZO, Gonzalo. El Principio de no Retroceso en el Campo de la Teoría Jurídica: el Progreso como Perdurabilidad para las Generaciones Futuras. In: PRIEUR, Michel; SOZZO, Gonzalo (Org.). La non régression en droit de l'environnement. Bruxelas: Bruylant, 2012.

WINTER, Gerd. Non Regression Principle in German Law. In: PRIEUR, Michel; SOZZO, Gonzalo (Org.). La non régression en droit de l'environnement. Bruxelas: Bruylant, 2012. p. 365-373.

Recebido em: 28/11/2013

Aceito em: 9/1/2014 